\title{
Decreto 5 del 2018. Año del centenario de la reforma universitaria
}

\section{8-AÑO DEL CENTENARIO DE LA REFORMA UNIVERSITARIA}

\author{
Decreto 5/2018
}

Declaración.

Ciudad de Buenos Aires, 05/01/2018

VISTO Y CONSIDERANDO:

Que en el año 2018 se cumplen CIEN (100) años de la Reforma Universitaria.

Que dicha Reforma tuvo sus origenes en el movimiento estudiantil que se inició en el año 1918 en la Universidad Nacional de Córdoba, REPÚBLICA ARGENTINA, y que sentó las principales bases del actual Sistema Universitario Nacional, tales como la autonomía universitaria, el cogobierno, la extensión universitaria, la libertad y periodicidad de las cátedras.

Que para celebrar su centenario, desde el MINISTERIO DE EDUCACIÓN, por intermedio de la Secretaria de Políticas Universitarias, se están llevando a cabo acciones conjuntas con las instituciones universitarias, los cuerpos académicos y estudiantiles, para diseñar e implementar propuestas que evoquen y analicen los cambios producidos en aquél entonces y reflexionar sobre el rol de la Universidad Pública en el Siglo XXI.

Que la presente norma tiene el propósito de acompañar el objetivo de evocar, analizar y actualizar el legado de esta gesta protagonizada por los estudiantes universitarios en el año 1918.

Que poniendo en valor el significado histórico y sus postulados en el actual Sistema Educativo Nacional, es que se propone resaltar en el año de su centenario, la Reforma Universitaria de 1918.

Que la presente medida se dicta en uso de las facultades conferidas por el artículo 99, inciso 1, de la CONSTITUCIÓN NACIONAL.

Por ello,

EL PRESIDENTE DE LA NACIÓN ARGENTINA

DECRETA:

ARTICULO $1^{\circ}$.- Declárase el Año 2018 como el "AÑO DEL CENTENARIO DE LA REFORMA UNIVERSITARIA".

ARTÍCULO $2^{\circ}$.- Dispónese que durante el Año 2018, toda la documentación oficial de la ADMINISTRACIÓN PÚBLICA NACIONAL, centralizada y descentralizada, así como en los Entes autárquicos dependientes de ésta, deberá llevar la leyenda "2018 - AÑO DEL CENTENARIO DE LA REFORMA UNIVERSITARIA".

Página 1 


\section{BOLETÍN OFICIAL}

de la República Argentina

ARTÍCULO $3^{\circ}$.- En orden a lo establecido en el artículo $1^{\circ}$ del presente, el PODER EJECUTIVO NACIONAL realizará acciones tendientes a rememorar, destacar y reflexionar junto a las instituciones universitarias y su comunidad académica y estudiantil, el significado de la Reforma Universitaria de 1918 y su legado.

ARTíCULO $4^{\circ}$.- Invítase a los Gobiernos Provinciales y al de la CIUDAD AUTÓNOMA DE BUENOS AIRES a adherir al presente decreto.

ARTíCULO $5^{\circ}$.- Comuníquese, publiquese, dése a la DIRECCIÓN NACIONAL DEL REGISTRO OFICIAL y archivese. — MACRI. — Marcos Peña.

e. $08 / 01 / 2018 \mathrm{~N}^{\circ} 1084 / 18$ v. $08 / 01 / 2018$ 


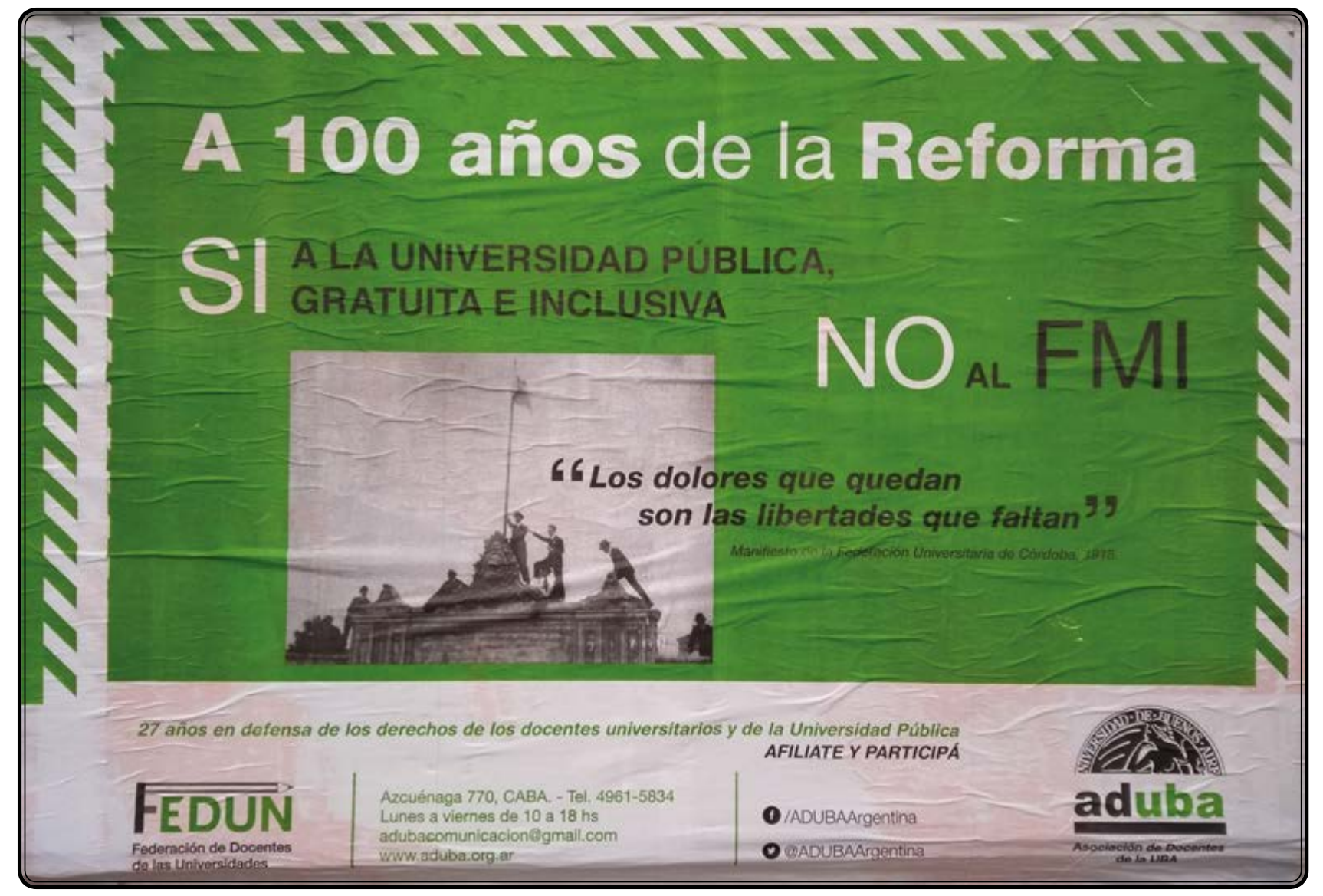

La búsqueda es el camino. 